Authors have nothing to disclose with regard to commercial support.

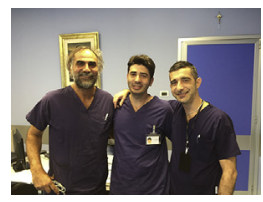

\section{AORTIC VALVE THERAPIES: DIFFERENT \\ APPROACHES AND \\ OUTCOMES}

\section{To the Editor:}

Today, several different approaches have become available for the treatment of aortic valve disease, including minimally invasive surgery and transcatheter aortic valve implantation (TAVI) through various vascular accesses. These strategies are to be considered integral to treatment, in that the diseased aortic valve can be approached both surgically and by transcatheter route, rather than surgically or by transcatheter route. An increasing number of scientific publications, however, tend to put the various approaches in competition. In this respect, patients undergoing transapical TAVI are generally at higher risk than those treated through the transfemoral route, whereas surgical patients are in general less frail than patients undergoing TAVI. As part of this debate, we read with interest the article by Furukawa and colleagues, ${ }^{1}$ who evaluated minimally invasive surgery as first-line treatment in intermediate-risk patients, compared with transfemoral TAVI and transapical TAVI, with the latter approach being reserved for patients with no peripheral vascular option. There are several aspects in the outcome analysis of this study that deserve special attention. Although the study groups were comparable in terms of preoperative risk, patients with transapical access had a 2 -fold higher mortality than did surgical patients and an almost 2fold higher mortality than patients with transfemoral access, as well as a much higher risk of low-output syndrome and major bleeding. It is also well known that TAVI procedures are associated with an increased risk of pacemaker implantation. In addition, no cost analysis is provided in the article, which does not allow the reader to make a comparison between these techniques with devices that have very different prices. It should also be stressed that these comparisons

\footnotetext{
The Editor welcomes submissions for possible publication in the Letters to the Editor section that consist of commentary on an article published in the Journal or other relevant issues. Authors should: $\bullet$ Include no more than 500 words of text, three authors, and five references. • Type with double-spacing. • See http://jtcs.ctsnetjournals.org/ misc/ifora.shtml for detailed submission instructions. • Submit the letter electronically via jtcvs.editorialmanager.com. Letters commenting on an article published in the JTCVS will be considered if they are received within 6 weeks of the time the article was published. Authors of the article being commented on will be given an opportunity of offer a timely response ( 2 weeks) to the letter. Authors of letters will be notified that the letter has been received. Unpublished letters cannot be returned.
}

require longer follow-up, given the debate surrounding the durability of TAVI prostheses as well as the incidence of significantly higher postimplant aortic insufficiency, also recorded in this study, and its impact on mortality.

Finally, the results from the first "real-world" studies undertaken in cardiac surgery centers diverge from those of clinical trials and are more in favor of surgical treatment than of transcatheter intervention. ${ }^{2}$ This is also why we reiterate the concept that different patients require different procedures, with cardiac surgeons being able to offer both procedures and tailor the approach to the individual patient.

Giuseppe Santarpino, $M D^{a, b}$
Luigi Specchia, $M D^{b}$
Marcello Melone, $M D^{b}$
Renato Gregorini, $M D^{b}$
${ }^{a}$ Paracelsus Medical University
Nuremberg, Germany
${ }^{b}$ Città di Lecce Hospital-GVM Care \& Research
Lecce, Italy

References

1. Furukawa N, Kuss O, Emmel E, Scholtz S, Scholtz W, Fujita B, et al Minimally invasive versus transapical versus transfemoral aortic valve implantation: a one-to-one-to-one propensity score-matched analysis. J Thorac Cardiovasc Surg. 2018;156:1825-34.

2. Armoiry X, Obadia JF, Pascal L, Polazzi S, Duclos A. Comparison of transcatheter versus surgical aortic valve implantation in high-risk patients: a nationwide study in France. J Thorac Cardiovasc Surg. 2018;156:1017-25.e4.

https://doi.org/10.1016/j.jtcvs.2018.06.087

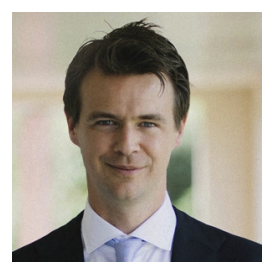

TRANSCATHETER
AORTIC VALVE
REPLACEMENT AND
SURGICAL AORTIC
VALVE REPLACEMENT:
BOTH EXCELLENT
THERAPIES

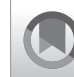

Reply to the Editor:

The introduction of transcatheter aortic valve replacement (TAVR) represents a paradigm shift in the treatment of aortic valve disease. Major trials have demonstrated the efficacy of TAVR in extreme-risk, high-risk, and intermediate-risk cohorts. ${ }^{1-5}$ The comparison of patients undergoing TAVR or surgical aortic valve replacement (SAVR) in nonrandomized postcommercialization registries is extraordinarily difficult. Commonly used risk assessment scores are derived from surgical patient data and do not take into account frailty, organ dysfunction, or impediments to undergoing a surgical procedure. Measures to assess frailty are underdeveloped; those that exist predict mortality better than either the Society of Thoracic Surgeons predicted risk of mortality or the euroSCORE. ${ }^{6}$ 